\title{
The Weighting Analysis of School Exam's Subject via Grey Structure Modeling
}

\author{
Yuan-Chieh Chin, Chung-Shih Huang, and Han-Chang Wang
}

\begin{abstract}
Technical and vocational education is an important human resources pool for existence and development of SMEs and traditional industries. After the educational reform in Taiwan, a large number of general high schools are established; therefore, the numbers of vocational high schools are deduced. Before 1990, the ratio of vocational high school and senior high school students is still seven to three. However, the ratio has become four to six so far. All of the students study hard in order to enter universities. This trend not only affects the basic technical manpower cultivation seriously, but also results in regressive economic construction. Hence, this paper tries to use vocational education as base, and applies the soft-computing method to analyze the testing subjects in vocational high schools. The research tries to find out the weighting and cluster of the subjects, which can be the basis of the professional fields in future technical and vocational education. Firstly, the mathematics model of grey structure modeling(GSM) is introduced, which is combine the localization grey relational grade(LGRG) with globalization grey relational grade (GGRG) in grey system theory. Secondly, an example in education is given to verify our new approach. In addition, the article also uses computing program to make the calculation steps more accurately and more quickly. As a result, it is hoped that through this method, the purpose of integrating exam's subject and the rational of clustering can be established.
\end{abstract}

Index Terms-Vocational high school, soft-computing weighting, clustering, GSM, LGRG, GGRG.

\section{INTRODUCTION}

In the analysis of weighting in real social system, there are many related methods had been presented in the past, such as AHP, factor analysis, ISM, Fuzzy method and grey system theory [1], [2]. Especially, in the education filed, some papers had presented, such as Research on evaluation model about students' scores [3], clustering in teacher-evaluating model [4], the activity processes of e-learning system [5], combine AHP method with GA method [6], multi factor analysis [7], and in the vocation school[8], [9]. However, the final results of the past research are very subjective, hence, the paper present an objective weighting analysis method. Combine the localization grey relational grade (LGRG) with the globalization grey relational grade (GGRG) in grey system theory as a new method, which is call grey structure modeling(GSM), to make the weighting can become more objective [10].

Manuscript received January 15, 2014; revised March 25, 2014.

Yuan-Chieh Chin and Han-Chang Wang are with the Electrical Engineering Department, Chienkuo Technology University, Changhua, Taiwan (e-mail: cyc@ctu.edu.tw, benson.eva@gmail.com).

Chung-Shih Huang is with the International Business Administration Department, Chienkuo Technology University, Changhua, Taiwan (e-mail: huang72@ctu.edu.tw).
The section II of this study are the mathematical model of localization grey relational grade and globalization grey relational grade, mainly explains the analysis steps of our research, Section III is the real example in the student exam score, and the actual data is substituted into the mathematical model to derive the results, The final section consists of a conclusion and recommendations for future research.

\section{MAthematics Model}

The mathematical foundation of grey relational grade can be described as follows

\section{A. Basic Concept}

\section{1) Factor space}

Assume $P(X)$ is one theme and $Q$ is one relationship. If a characteristic exists with key factors, such as: countable intention factor, expansion of factor and independence factor for the combination of $\{P(X) ; Q\},\{P(X) ; Q\}$, then it can be called a Factor space [11].

2) The comparison of sequence

Assume a sequence as

$$
\begin{array}{r}
x_{i}(k)=\left(x_{1}(k), x_{2}(k) \cdots, \cdots, x_{n}(k)\right) \\
k=1,2,3, \ldots n \in N, i=1,2,3, \ldots, n \in N
\end{array}
$$

and meet non-dimensional; scaling and polarization three conditions. Thus, this sequence is comparable.

\section{3) The four axioms of grey relational measurement}

When the space is formed by meeting factor space and comparability, the space is called grey relational space and is demonstrated by $\{P(X) ; \Gamma\}$, in which $\{P(X)\}$ is the theme and $\Gamma$ is the measurement tool. $\{P(X) ; \Gamma\}$ have normality; duality Symmetric; wholeness and closeness four axioms.

According to the above descriptions, if a function $\gamma\left(x_{i}, x_{j}\right) \in \Gamma$ can be found to meet all of the above four axioms, $\gamma\left(x_{i}, x_{j}\right)$ is considered as a grey relational grade.

\section{B. Grey Relational Grade}

In grey relational space $\{P(X) ; \Gamma\}$, exist the sequences $x_{i}\left(x_{i}(1), x_{i}(2),, \cdots, x_{i}(k)\right) \in X$. where $i=0,1,2, \cdots, m, k=1,2,3, \cdots, n \in N$ and

$$
\begin{aligned}
x_{0} & =\left(x_{0}(1), x_{0}(2), \cdot, \cdot \cdot, x_{0}(k)\right) \\
x_{1} & =\left(x_{1}(1), x_{1}(2), \cdot \cdot \cdot, x_{1}(k)\right) \\
\vdots & =\vdots \\
x_{m} & =\left(x_{m}(1), x_{m}(2), \cdot, \cdot, x_{m}(k)\right)
\end{aligned}
$$


In grey relational grade, if we take $x_{0}(k)$ as the reference sequence, and the others sequences are inspected sequences, then, it called "localization grey relational grade(LGRG)", if each sequence $x_{i}(k)$ can be the reference sequence, then, it called "globalization grey relational grade(GGRG)". In our research, we focus on Nagai's grey relational grade [12].

1) Localization grey relational grade

$$
\Gamma_{0 i}=\Gamma\left(x_{0}(k), x_{i}(k)\right)=\frac{\bar{\Delta}_{\text {max. }}-\bar{\Delta}_{0 i}}{\bar{\Delta}_{\text {max. }}-\bar{\Delta}_{\min .}}
$$

in which

$$
\bar{\Delta}_{0 i}=\left\|x_{0 i}\right\|_{2}=\left(\sum_{k=1}^{n}\left[\Delta_{0 i}(k)\right]^{2}\right)^{\frac{1}{2}}
$$

where

$$
i=1,2,3, \cdots, m, \quad k=1,2,3, \cdots, n, j \in I
$$

1) $x_{0}$ : Reference sequence, $x_{i}$ : Inspected sequences

2) $\Delta_{o i}(k)=\left\|x_{0}(k)-x_{i}(k)\right\|$ : The difference between $x_{0}$ and $x_{i}$ norm).

3) $\Delta_{\text {min. }}=\underset{j \in i}{\forall} \forall k\left\|x_{0}(k)-x_{j}(k)\right\|$

4) $\Delta_{\text {max. }}=\underset{j \in i}{\forall} \forall k\left\|x_{0}(k)-x_{j}(k)\right\|$

\section{2) The grey relational ordinal}

After the grey relational grade is calculated, according the value, we can rank the sequence, and this procedure is called grey relational rank. For reference sequences $x_{0}$, and inspected sequences are $x_{i}$, if $\Gamma\left(x_{0}, x_{i}\right) \geq \Gamma\left(x_{0}, x_{j}\right)$ then we found that under the reference sequence $x_{0}$, the grey relational rank of $x_{i}$ is greater than grey relational rank of $x_{j}$

\section{3) Globalization grey relational grade}

In the definition of globalization grey relational grade, each sequence can be the reference sequence. In this section, we still use Nagai's grey relational grade as our mathematics model.

$$
\Gamma_{i j}=\Gamma\left(x_{i}, x_{j}\right)=1-\frac{\bar{\Delta}_{i j}}{\Delta_{\max .}}
$$

where

$$
\bar{\Delta}_{i j}=\left(\sum_{k=1}^{n}\left[\Delta_{i j}(k)\right]^{2}\right)^{\frac{1}{2}}
$$

When the results are found, we can use the eigenvector method to rank the sequence, and then chose the optimal one. The whole steps are illustrated below:

1) Constructing the relative weighting matrix $[R]_{m \times m}$, which is called "grey relational matrix".

2) Finding the eigenvalue for the relative weighting matrix $A R=\lambda R$

3) Using eigenvector method to find the weighting for each

$$
\text { target } P^{-1} R P=\operatorname{diag}\left\{\lambda_{1}, \lambda_{2}, \lambda_{3, \ldots . .} \lambda_{n}\right\}
$$

4) The maximum $\lambda_{\max }$ corresponding eigenvector are the weighting value for whole sequences.

$$
R_{m \times m}=\left[\begin{array}{cccc}
\Gamma_{11} & \Gamma_{12} & \ldots & \Gamma_{1 m} \\
\Gamma_{21} & \Gamma_{22} & \ldots & \Gamma_{2 m} \\
\vdots & \vdots & \ddots & \Gamma_{11} \\
\Gamma_{m 1} & \Gamma_{m 2} & \ldots & \Gamma_{m m}
\end{array}\right]
$$

\section{Grey System Modeling}

The grey system modeling (GSM) refers to the integration of LGRA and GGRA in the grey theory while GGRA represents $\mathrm{X}$ axis vector, LGRA represents $\mathrm{Y}$ axis vector [11]. That is, there is a group of flat coordinates for each analyzed object; then, the clustering concept is used to make the flat coordinates hierarchical, which transforms the previous analysis by one-dimensional space to two-dimensional space.

\begin{tabular}{|c|c|c|c|c|c|}
\hline Subject & Chinese & English & Mathematics & $\begin{array}{l}\text { Digital } \\
\text { logical }\end{array}$ & Electronic \\
\hline Weighting & 3 & 2 & 4 & 3 & 3 \\
\hline No. 01 & 85 & 94 & 100 & 70 & 82 \\
\hline No. 02 & 89 & 90 & 90 & 73 & 46 \\
\hline No. 03 & 68 & 82 & 75 & 78 & 68 \\
\hline No. 04 & 81 & 78 & 95 & 65 & 92 \\
\hline No. 05 & 74 & 84 & 80 & 85 & 82 \\
\hline No. 06 & 76 & 59 & 95 & 83 & 78 \\
\hline No. 07 & 68 & 55 & 65 & 58 & 13 \\
\hline No. 08 & 58 & 66 & 80 & 60 & 46 \\
\hline No. 09 & 83 & 97 & 90 & 93 & 93 \\
\hline No. 10 & 75 & 86 & 100 & 100 & 100 \\
\hline No. 11 & 64 & 38 & 45 & 35 & 8 \\
\hline No. 12 & 75 & 75 & 85 & 65 & 83 \\
\hline No. 13 & 68 & 50 & 65 & 60 & 32 \\
\hline No. 14 & 66 & 78 & 85 & 53 & 34 \\
\hline No. 15 & 69 & 64 & 75 & 35 & 46 \\
\hline No. 16 & 68 & 46 & 45 & 30 & 18 \\
\hline No. 17 & 70 & 72 & 75 & 73 & 82 \\
\hline No. 18 & 80 & 91 & 95 & 83 & 97 \\
\hline No. 19 & 88 & 72 & 95 & 63 & 72 \\
\hline No. 20 & 58 & 53 & 75 & 45 & 53 \\
\hline No. 21 & 68 & 47 & 60 & 45 & 29 \\
\hline No. 22 & 68 & 75 & 100 & 78 & 61 \\
\hline No. 23 & 74 & 65 & 95 & 68 & 47 \\
\hline No. 24 & 73 & 61 & 65 & 53 & 31 \\
\hline No. 25 & 76 & 75 & 95 & 58 & 70 \\
\hline No. 26 & 44 & 40 & 45 & 43 & 8 \\
\hline No. 27 & 84 & 82 & 90 & 68 & 93 \\
\hline No. 28 & 66 & 56 & 95 & 63 & 73 \\
\hline No. 29 & 61 & 49 & 80 & 80 & 78 \\
\hline No. 30 & 80 & 78 & 95 & 93 & 85 \\
\hline No. 31 & 73 & 88 & 75 & 80 & 47 \\
\hline No. 32 & 54 & 80 & 70 & 55 & 53 \\
\hline No. 33 & 54 & 76 & 60 & 38 & 35 \\
\hline No. 34 & 73 & 82 & 65 & 58 & 32 \\
\hline No. 35 & 54 & 26 & 45 & 43 & 5 \\
\hline No. 36 & 68 & 83 & 85 & 65 & 43 \\
\hline No. 37 & 73 & 72 & 90 & 78 & 44 \\
\hline No. 38 & 82 & 57 & 85 & 68 & 32 \\
\hline No. 39 & 23 & 60 & 72 & 30 & 19 \\
\hline No. 40 & 60 & 60 & 35 & 73 & 43 \\
\hline No. 41 & 69 & 39 & 55 & 65 & 29 \\
\hline No. 42 & 85 & 71 & 95 & 68 & 72 \\
\hline Average & 69.6429 & 67.9048 & 77.6667 & 63.7381 & 53.6667 \\
\hline
\end{tabular}
The paper uses the method that proposed by Nagai because the values of the other three quantitative grey relational grade won't be zero, and only Nagai's method can reach the values between 0 and 1 . Therefore, it can become a two-dimensional space.

TABLE I: THE SCORE OF FIRST MIDDLE TEST 


\section{REAL EXAMPLE}

\section{A. Subject of Analysis and Test Score}

In this paper, National Taichung Industrial High School, Division of Information Engineering, $1^{\text {st }}$ grade students in a class of 42 students are used for the study. And the middle test of is taken. The results of the exam are shown in Table I and Table II [13].

TABLE II: THE SCORE OF SECOND MIDDLE TEST

\begin{tabular}{|c|c|c|c|c|c|}
\hline Subject & Chinese & English & Mathematics & $\begin{array}{l}\text { Digital } \\
\text { logical }\end{array}$ & Electronic \\
\hline Weighting & 3 & 2 & 4 & 3 & 3 \\
\hline No. 01 & 82 & 76 & 90 & 65 & 53 \\
\hline No. 02 & 84 & 71 & 90 & 95 & 77 \\
\hline No. 03 & 90 & 86 & 95 & 70 & 78 \\
\hline No. 04 & 82 & 80 & 85 & 95 & 73 \\
\hline No. 06 & 73 & 78 & 90 & 68 & 66 \\
\hline No. 07 & 63 & 50 & 85 & 55 & 54 \\
\hline No. 08 & 72 & 81 & 90 & 73 & 67 \\
\hline No. 09 & 81 & 92 & 75 & 97 & 87 \\
\hline No. 10 & 77 & 73 & 85 & 73 & 67 \\
\hline No. 11 & 58 & 58 & 65 & 48 & 32 \\
\hline No. 13 & 64 & 46 & 90 & 80 & 56 \\
\hline No. 14 & 85 & 89 & 90 & 63 & 81 \\
\hline No. 15 & 71 & 60 & 75 & 60 & 43 \\
\hline No. 16 & 74 & 31 & 70 & 35 & 37 \\
\hline No. 17 & 77 & 60 & 90 & 65 & 69 \\
\hline No. 18 & 83 & 80 & 95 & 90 & 85 \\
\hline No. 19 & 71 & 73 & 55 & 63 & 50 \\
\hline No. 20 & 58 & 58 & 65 & 40 & 37 \\
\hline No. 21 & 96 & 74 & 90 & 73 & 69 \\
\hline No. 22 & 83 & 85 & 80 & 79 & 56 \\
\hline No. 23 & 53 & 46 & 50 & 40 & 39 \\
\hline No. 24 & 76 & 65 & 80 & 73 & 61 \\
\hline No. 25 & 74 & 58 & 85 & 60 & 70 \\
\hline No. 26 & 85 & 84 & 80 & 82 & 83 \\
\hline No. 27 & 84 & 74 & 85 & 100 & 64 \\
\hline No. 28 & 50 & 84 & 65 & 53 & 48 \\
\hline No. 29 & 65 & 20 & 65 & 55 & 18 \\
\hline No. 30 & 74 & 25 & 65 & 50 & 30 \\
\hline No. 31 & 89 & 96 & 90 & 75 & 54 \\
\hline No. 32 & 64 & 67 & 85 & 60 & 53 \\
\hline No. 33 & 56 & 40 & 85 & 38 & 56 \\
\hline No. 34 & 63 & 65 & 70 & 53 & 33 \\
\hline No. 35 & 78 & 65 & 80 & 48 & 48 \\
\hline No. 36 & 91 & 86 & 85 & 88 & 97 \\
\hline No. 37 & 54 & 60 & 75 & 43 & 43 \\
\hline No. 38 & 44 & 32 & 55 & 63 & 41 \\
\hline No. 39 & 60 & 51 & 75 & 40 & 41 \\
\hline No. 40 & 80 & 60 & 70 & 48 & 37 \\
\hline No. 41 & 78 & 54 & 60 & 55 & 52 \\
\hline No. 42 & 82 & 76 & 90 & 65 & 53 \\
\hline Average & 72.8333 & 65.2143 & 79.1667 & 65.3809 & 57.2381 \\
\hline
\end{tabular}

\section{B. Calculation Results for First Test}

By utilizing the model presented in this paper, the comparison of points of 42 students is used as a case. The working method is as follows [14], [15]:

\section{1) Build the standard sequence}

Takes the larger the better of test subject for each student to get the standard sequence $x_{0}$, fro example, the No. 1 student is 100 , and No. 2student is 90 , and so on. Hence, $x_{0}=(100,90,82, \ldots, 73,69,95)$

2) Based on Table III, the each sequence are shown below

$$
\begin{aligned}
& x_{1}=\text { Chinese }=(85,89,68, \ldots, 60,69,85) \\
& x_{2}=\text { English }=(94,90,82, \ldots, 60,39,71)
\end{aligned}
$$

$$
\begin{gathered}
x_{3}=\text { Mathematics }=(100,90,75, \ldots, 35,55,95) \\
x_{4}=\text { Digital logical }=(70,73,78, \ldots, 73,65,68) \\
x_{5}=\text { Electronic }=(82,46,68, \ldots, 43,29,72)
\end{gathered}
$$

\begin{tabular}{|c|c|c|c|}
\hline $\begin{array}{l}\text { Student and } \\
\text { output data }\end{array}$ & $\begin{array}{l}\text { The larger } \\
\text { the better }\end{array}$ & $\begin{array}{l}\text { Student and } \\
\text { output data }\end{array}$ & $\begin{array}{l}\text { The larger } \\
\text { the better }\end{array}$ \\
\hline No. 01 & 100 & No. 22 & 100 \\
\hline No. 02 & 90 & No. 23 & 95 \\
\hline No. 03 & 82 & No. 24 & 73 \\
\hline No. 04 & 95 & No. 25 & 95 \\
\hline No. 06 & 95 & No. 27 & 93 \\
\hline No. 07 & 68 & No. 28 & 95 \\
\hline No. 08 & 80 & No. 29 & 80 \\
\hline No. 09 & 97 & No. 30 & 95 \\
\hline No. 10 & 100 & No. 31 & 88 \\
\hline No. 11 & 64 & No. 32 & 80 \\
\hline No. 13 & 68 & No. 34 & 82 \\
\hline No. 14 & 85 & No. 35 & 54 \\
\hline No. 15 & 75 & No. 36 & 85 \\
\hline No. 16 & 68 & No. 37 & 90 \\
\hline No. 17 & 82 & No. 38 & 85 \\
\hline No. 18 & 97 & No. 39 & 72 \\
\hline No. 19 & 95 & No. 40 & 73 \\
\hline No. 20 & 75 & No. 41 & 69 \\
\hline No. 21 & 68 & No. 42 & 95 \\
\hline
\end{tabular}

TABLE III: THE STANDARD SEQUENCE

3) Calculate the localization grey relational grade

Through equation (3), the steps are

- $\Delta_{01}=108.3097, \Delta_{02}=119.1554, \Delta_{03}=61.2862$,

$\Delta_{04}=147.2379, \Delta_{05}=222.6252$

- $\Delta_{\text {max. }}=222.6252, \Delta_{\text {min. }}=61.2862$

- $\gamma_{01}=0.7085, \gamma_{02}=0.6413, \gamma_{03}=1.0000, \gamma_{04}=0.4673$ and $\gamma_{05}=0.0000$

4) Calculate the globalization grey relational grade Also through Eq. (4) to get the grey relational matrix.

$$
R_{5 \times 5}=\left[\begin{array}{lllll}
1.0000 & 0.4094 & 0.4421 & 0.4858 & 0.0778 \\
0.4904 & 1.0000 & 0.4216 & 0.4592 & 0.1732 \\
0.4421 & 0.4026 & 1.0000 & 0.3049 & 0.0000 \\
0.4858 & 0.4592 & 0.3049 & 1.0000 & 0.2923 \\
0.0778 & 0.1732 & 0.0000 & 0.2923 & 1.0000
\end{array}\right]
$$

The maximum $\lambda_{\max }=2.3634$, and corresponding eigenvector are [0.5131, 0.5115, 0.4353, 0.4954, 0.2005]

5) The weighting and the rank of subject are shown in Table IV

\begin{tabular}{ccc}
\multicolumn{2}{c}{ TABLE IV: THE WEIGHTING VALUE OF EACH SUBJECT } \\
\hline \hline Subject & LGRG & GGRG \\
\hline Chinese & 0.7085 & 0.5131 \\
English & 0.6413 & 0.5115 \\
Mathematics & 1.0000 & 0.4353 \\
Digital logical & 0.4673 & 0.4954 \\
Electronic & 0.0000 & 0.2005 \\
\hline
\end{tabular}

\section{Calculation Results for Second Test}

Same as mentioned below steps:

1) Build the standard sequence

$$
x_{0}=(90,90,95, \ldots, 80,78,90)
$$


TABLE V: THE STANDARD SEQUENCE

Student and output data The larger Student and output data The larger the better the better

\begin{tabular}{lccc} 
No. 01 & 90 & No. 22 & 85 \\
No. 02 & 95 & No. 23 & 53 \\
No. 03 & 95 & No. 24 & 80 \\
No. 04 & 95 & No. 25 & 85 \\
No. 05 & 90 & No. 26 & 85 \\
No. 06 & 90 & No. 27 & 100 \\
No. 07 & 85 & No. 28 & 84 \\
No. 08 & 90 & No. 29 & 65 \\
No. 09 & 97 & No. 30 & 74 \\
No. 10 & 85 & No. 31 & 96 \\
No. 11 & 65 & No. 32 & 85 \\
No. 12 & 100 & No. 33 & 85 \\
No. 13 & 90 & No. 34 & 70 \\
No. 14 & 90 & No. 35 & 80 \\
No. 15 & 75 & No. 36 & 97 \\
No. 16 & 74 & No. 37 & 75 \\
No. 17 & 90 & No. 38 & 63 \\
No. 18 & 95 & No. 39 & 75 \\
No. 19 & 73 & No. 40 & 80 \\
No. 20 & 65 & No. 41 & 78 \\
No. 21 & 96 & No. 42 & 90 \\
\hline
\end{tabular}

2) Based on TABLE II, the each sequence are shown below

$$
\begin{gathered}
x_{1}=\text { Chinese }=(82,84,90, \ldots, 60,80,78) \\
x_{2}=\text { English }=(76,71,86, \ldots, 51,60,41) \\
x_{3}=\text { Mathematics }=(90,90,95, \ldots, 75,70,60) \\
x_{4}=\text { Digital logical }=(65,95,70, \ldots, 40,48,55) \\
x_{5}=\text { Electronic }=(53,77,78, \ldots, 41,37,52)
\end{gathered}
$$

3) Calculate the localization grey relational grade Through equation (3), the steps are

- $\Delta_{01}=95.1473, \Delta_{02}=149.7565, \Delta_{03}=49.7896, \Delta_{04}=$ $138.6759, \Delta_{05}=182.5185$

- $\Delta_{\text {max. }}=182.5185, \Delta_{\text {min. }}=49.7896$

- $\gamma_{01}=0.6583, \gamma_{02}=0.2468, \gamma_{03}=1.0000, \gamma_{04}=0.3303$ and $\gamma_{05}=0.0000$

4) Calculate the globalization grey relational grade Also through Eq. (4) to get the grey relational grade.

$$
\begin{gathered}
\Delta_{i j}=\left[\begin{array}{ccccc}
0.0000 & 107.7404 & 84.6286 & 111.2565 & 134.0746 \\
107.7404 & 0.0000 & 137.2589 & 111.0675 & 103.08253 \\
86.6286 & 137.2589 & 0.0000 & 130 . .5680 & 161.9815 \\
111.2565 & 111.0675 & 130.5680 & 0.0000 & 1101.4495 \\
134.0746 & 103.0825 & 161.9815 & 101.4495 & 0.0000
\end{array}\right] \\
\Delta_{5 \times 5}=\left[\begin{array}{ccccc}
1.0000 & 0.3349 & 0.4775 & 0.3132 & 0.1723 \\
0.3349 & 1.0000 & 0.1526 & 0.3143 & 0.3636 \\
0.4775 & 0.1526 & 1.0000 & 0.1939 & 0.0000 \\
0.3132 & 0.3143 & 0.1939 & 1.0000 & 0.3737 \\
0.1723 & 0.3626 & 0.0000 & 0.3737 & 1.0000
\end{array}\right]
\end{gathered}
$$

The maximum $\lambda_{\max }=2.0933$, and corresponding eigenvector are [0.5029, 0.4729, 0.3686, 0.4788, 0.3980]

5) The weighting and the rank of subject are shown in Table VI

TABLE VI: The WeIGHTING VALUE of EACH SubJECT

\begin{tabular}{ccc}
\hline \hline Subject & LGRG & GGRG \\
\hline Chinese & 0.6583 & 0.5029 \\
English & 0.2468 & 0.4729 \\
Mathematics & 1.0000 & 0.3686 \\
Digital logical & 0.3303 & 0.4788 \\
Electronic & 0.0000 & 0.3980 \\
\hline
\end{tabular}

\section{The Toolbox}

The cluster of exam subject are shown in Fig. 1 and Fig. 2 [16], [17].

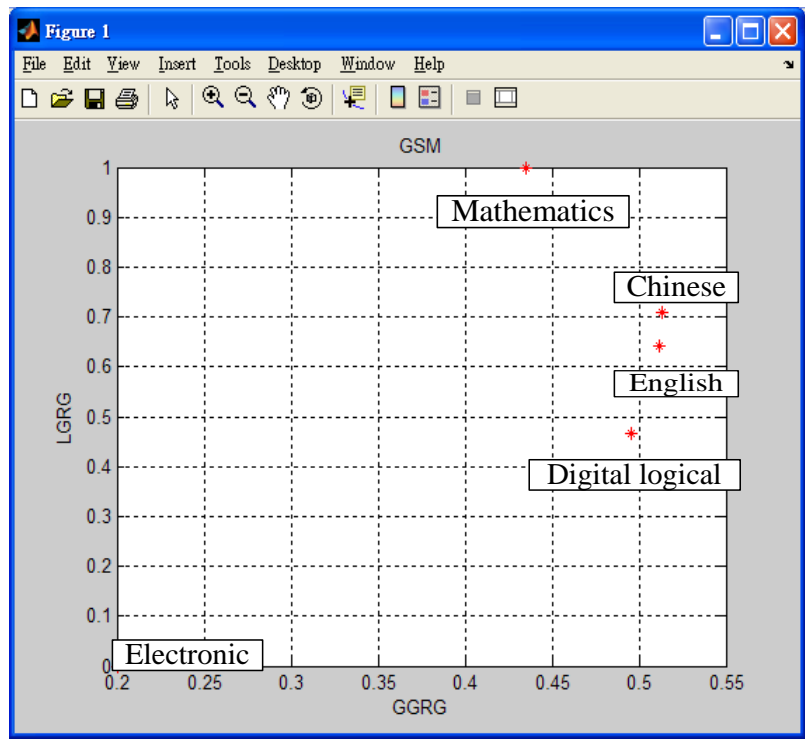

Fig. 1. The results of GSM for $1^{\text {st }}$ test.

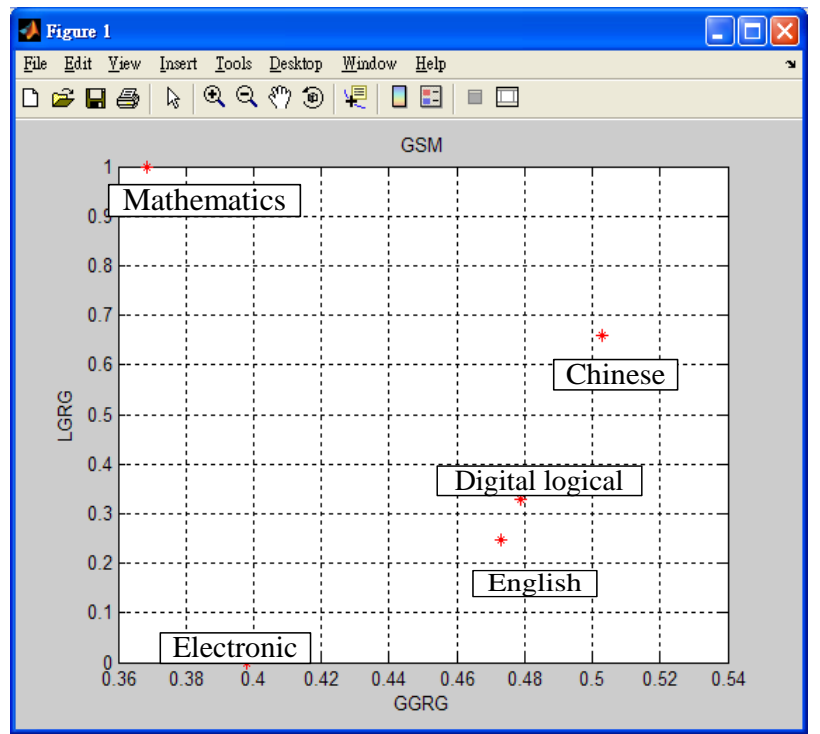

Fig. 2. The results of GSM for $2^{\text {nd }}$ test.

\section{CONCLUSION}

For vocational high school students, the development of vocational education in Taiwan has become science and technology universities. However, the graduates not only lack professional skills, but they are also worse than the 
general university graduates in the knowledge development. Finally, their key features disappear. The article uses vocational education as base, and applies soft-computing methods, combing localization grey relational grade with globalization grey relational grade in the grey system theory as a new approach. Also, the self-developed computer toolbox is used to analyze the data, through the examples to get the objective weighting and cluster for exam's subject to be the basic reference for future vocational education professional fields. It is hoped that this could shorten the standard of vocational and general university systems.

Through the actual calculation, we found that math and electronics are clustered while Chinese, English and digital logic are clustered. Especially, after two times tests, the results are the same. Moreover, the results are not only in accordance with traditional recognition, but also prove the reasonableness of the objectivity of the analysis presented in this paper.

To sum up, the paper only used one of mathematics method in the grey system theory to transfer the subjective type into objective type. In the future, it is suggested to increase the other soft-computing calculation method and expand to range in others application of vocational education to double verifies the final result.

\section{ACKNOWLEDGMENT}

The authors want to heartily thank Professor Kun-Li Wen, to provide the toolbox to help the huge data calculation.

\section{REFERENCES}

[1] T. L. Saaty, Principia Mathematica Decernendi: Mathematical Principles of Decision Making, Pittsburgh, Pennsylvania: RWS Publications, USA, 2010.

[2] Y. C. Chin, "A study on the application of grey entropy and rough set method to the weighting of relevant subjects in elementary school test scores," Journal of Grey System, vol. 16, no. 4, pp. 217-224, 2013.

[3] N. Xiao and K. H. Hou, "Research on evaluation model about students' scores for mechanical and electronic comprehensive experiment course," in Proc. International Conference on Information Management, Innovation Management and Industrial Engineering, vol. 3, 2011, pp. 583-586.

[4] N. Y. Shi, K. Chen, and C. H. Li, "The application of fuzzy clustering in teacher-evaluating model," in Proc. IEEE International Symposium on Medicine \& Education, 2009, pp. 872-875.

[5] C. S. Wang and S. L. Lin, "Combining fuzzy AHP and association rule to evaluate the activity processes of e-learning system," in Proc. $6^{\text {th }}$ International Conference on Genetic and Evolutionary Computing, 2012, pp. 566-570.

[6] J. L. Yu and B. S. Sun, "Research of education evaluation information mining technology based on Analytical Hierarchy Process (AHP) and Genetic Algorithm (GA)," in Proc. $3^{\text {rd }}$ International Conference on Advanced Computer Theory and Engineering, vol. 4, 2010, pp. V4-289-V4-292.
[7] C. Z. Feng, "Multiple factor analysis and its application in integrating university evaluation indicators," Renmin University of China Education Journal, no. 1, pp. 42-53, 2013.

[8] Y. Liang, H. Zeng, F. Wang, Y. Chen, and Y. Sun, "Research on the fuzzy comprehensive quality evaluation method of the research oriented courses of the higher vocational colleges," in Proc. $1^{\text {st }}$ International Workshop on Education Technology and Computer Science, 2009, pp. 425-428.

[9] P. S. Zhang and J. G. Hu, "Application of fuzzy hierarchy evaluation in the occupational competency assessment of the vocational colleges," in Proc. International Symposium on Information Technology in Medicine and Education, vol. 1, 2012, pp. 182-185.

[10] M. L. You, W. F. Hsieh, P. J. Chen, and K. L. Wen, "The development of GSM toolbox and its application in outstanding teacher assessment \& 300m man's race," Journal of Grey System, vol. 15, no. 3, pp. 151-158, 2012.

[11] K. L. Wen, Grey System Theory, 2nd Edition, Wunan Publisher, Taipei, 2013.

[12] M. Nagai and D. Yamaguchi, The Application of Grey System Theory for Engineer and Student, Tokyo: Kyuritsu Publisher, 2004.

[13] Y. C. Chin, H. C. Chen, H. I. Chen, and K. L. Wen, "Appling rough set method to analyze the weighting of relevant subjects in elementary school test scores," in Proc. 2013 International Conference on Fuzzy Theory and Its Application, 201 3, pp. 65-70.

[14] National Taichung Industrial High School, The Exam's Score of Division of Information Engineering, Taichung, 2013.

[15] K. L. Wen, M.-L. You, and J. R. Wang, "The modern analysis method in Kensei engineering," International Journal of Kansei Information, vol. 1, no. 1, pp. 43-52, 2010.

[16] J. S. Roger, Matlab Program Design, Hsinchhu: TeraSoft Inc, 2006.

[17] Y. F. Ding and K. L. Wen, MATLAB Program Design and Practices, Taipei: Wunan Publisher, 2012.

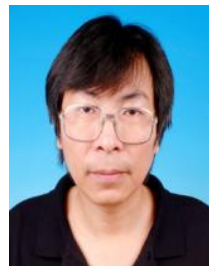

Yuan-Chieh Chin was born in Taichung, Taiwan in 1959. He received his master degree of electrical engineering in 1992 from National Changhua Education University, Changhua, Taiwan, and received the Ph.D degree from the National Chung Cheng University in 2008. His main employment experience was the Industrial Technology Research Institute. $\mathrm{He}$ is an associate professor in the Department of Electrical Engineering at Chienkuo Technology University, Taiwan. His areas of research interest include electric engineering education, interface technology, and power applications.

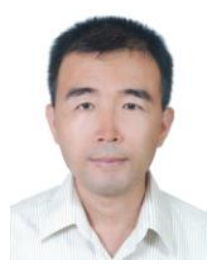

Chung-Shih Huang was born in Tainan, Taiwan in 1968. He received his Ph. D. degree from Takushoku University, Japan, 2002. He is currently a lecturer in the Department of International Business Administration at Chienkuo Technology University, Taiwan. His areas of research interest include business management, Japanese and marketing management.

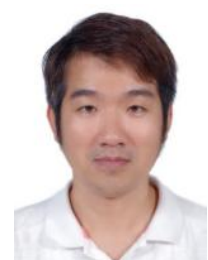

Han-Chang Wang was born in Tainan, Taiwan in 1969 He received the B.S. degree of informational engineering in 1995 from Fengchia University, Taichung, Taiwan, and master program in education in National Changhua Education University, Changhua, Taiwan. $\mathrm{He}$ is currently a teacher in the division of information engineering, National Taichung Industrial High School. His areas of research interests include information engineering and grey system analysis. 